Psychopharmacologia (Berl.) 26, 115-126 (1972)

(C) by Springer-Verlag 1972

\title{
The Effects of Chlorpromazine on Psychomotor Stimulant Self-Administration in the Rhesus Monkey*
}

\author{
M. C. WILSON** and C. R. Sohuster *** \\ Pharmacology Department, University of Michigan, Medical School \\ Ann Arbor, Michigan
}

Received April 1, 1971; Final Version December 21, 1971

\begin{abstract}
The effects of acute and chronic chlorpromazine treatment on psychomotor stimulant self-administration behavior in the Rhesus monkey were determined. Chlorpromazine treatment significantly increased the frequency of self-administration of cocaine, pipradrol, phenmetrazine, $d$-amphetamine and methylphenidate. The basis of this effect was thought to either be due to an antagonism of the reinforcing effect of these compounds or an antagonism of those actions of the psychomotor stimulants which may function in limiting their selfadministration.
\end{abstract}

Key words: Self-Administration-Cocaine-Chlorpromazine-PhenmetrazineMethylphenidate.

The relationships between response rate and magnitude of reinforcement and between magnitude of reinforcement and total drug intake have been studied in rats and in monkeys which self-administered various psychomotor stimulants (Pickens et al., 1967; Pickens and Harris, 1968; Deneau and Inoki, 1967; and Wilson et al., 1971). These investigators found that an inverse relationship existed between infusion dosage, i.e., magnitude of reinforcement and frequency of self-administration. Furthermore, total daily drug intake was independent of infusion dosage over a wide range of dosages.

These results indicate that either a direct effect of the drug being self-administered or some central mechanism is functioning to limit drug intake. In either case, one should be able to produce changes in drug intake by treatment with other compounds. These treatment drugs may either potentiate or block effects of psychomotor stimulants or

* This study was supported by NIMH Grant No. 5r-10MH-12084 and by NIMH Grant No. MH-18245-01.

** Presently located in the Department of Pharmacology, School of Pharmacy, University of Mississippi, University, Mississippi.

*** Presently located in the Department of Psychiatry, University of Chicago, Chicago, Illinois. 
interact in some manner with a central regulating mechanism which may function in limiting drug intake.

The present study was designed to determine if treatment with chlorpromazine, which has been shown to antagonize many behavioral and physiological effects of the psychomotor stimulants, would significantly alter the amount of these compounds which would be self-administered.

\section{Method}

The subjects were eight adult Rhesus monkeys, weighing between 4.2 and $5.5 \mathrm{~kg}$. They were permanently housed in individual open-faced experimental cubicles which have been previously described (Wilson et al., 1971). Each cubicle contained a stimulus light and lever. Subject restraint was accomplished by a stainless steel arm and harness which permitted relatively free movement (Yanagita et al., 1965). After each subject had adapted to this environmental situation for seven days, he was prepared with a chronic indwelling jugular catheter (Wilson et al., 1971).

When the stimulus light was illuminated, a single depression of the lever with at least $100 \mathrm{~g}$ of force activated an injection unit. This resulted in the intravenous administration of a given volume of drug solution or of physiologic saline.

Following catheter implantation, each subject was returned to his cubicle and the stimulus light was illuminated twenty-four hours a day for seven days. Each lever-press made during this period resulted in the administration of $0.2 \mathrm{cc} / \mathrm{kg}$ of sterile physiologic saline. During an injection cycle, which lasted $45-60$ sec depending on subject weight, the stimulus light was turned off and lever presses had no consequence. Each subject's lever-pressing frequeney for saline was determined during this period and this value served as a control.

Following this seven day period, the saline wasreplaced with $1.0 \mathrm{mg} / \mathrm{cc}$ solution of cocaine hydrochloride in sterile physiologic saline. Initially, the subjects had unlimited access to the cocaine and each lever-press resulted in the administration of $0.2 \mathrm{mg} / \mathrm{kg}$ of cocaine hydrochloride. New solutions were prepared every two days and the old solutions were discarded. Once a subject had initiated increased self-administration behavior as compared to that observed with saline, the drug access period was reduced from twenty-four to four hours daily. This was done to reduce the neurotoxic effects of cocaine which develop within five to seven days if subjects are allowed unlimited access to cocaine. Furthermore, this limited access schedule resulted in stable $( \pm 10 \%)$ daily cocaine intake. The drug access period, which was from 11:00 a.m. to 3:00 p.m., was indicated by the illumination of the stimulus light. During the period between sessions, lever presses were recorded but had 
no consequence. Each subject self-administered cocaine under these limited access conditions for three weeks.

At this time, the schedule of reinforcement was changed for four of the eight subjects. Two of the subjects were required to press the lever ten times before they received an injection of cocaine; twenty-five responses were required for the other two subjects. Therefore, four subjects were on FR-1, two on FR-10, and two on FR-25 schedule of reinforcement. The amount of cocaine received per injection was $0.2 \mathrm{mg} / \mathrm{kg}$ in all subjects except those on the FR-25 schedule of reinforcement. In these subjects the unit dosage was $0.1 \mathrm{mg} / \mathrm{kg}$ per injection. Furthermore, the drug access period was reduced to two hours in those subjects on the FR10 and FR-25 schedules of reinforcement. The subjects on the FR-10 and FR-25 schedules of reinforcement were run for an additional two weeks until daily drug intake had stabilized. Pretreatment studies were begun in the other four subjects during this time. Both acute and chronic chlorpromazine pretreatment studies were conducted in the subjects on the FR-1 schedule of reinforcement; however, only acute pretreatment experiments were conducted in the subjects on the FR-10 and FR-25 schedules.

a) Acute Pretreatment (Cocaine). Six different dosages of chlorpromazine ranging from 0.125 to $8.0 \mathrm{mg} / \mathrm{kg}$ were studied in each of the eight subjects and each dosage was tested once in each subject. The chlorpromazine was dissolved in sterile physiologic saline and all solutions were prepared on the day on which they were to be administered. The solutions were administered intramuscularly five minutes prior to the onset of the drug access period. The volume of the pretreatment injection was $1.0 \mathrm{cc}$, and this was held constant throughout the study.

b) Chronic Pretreatment (Cocaine). Following completion of the acute pretreatment study in those subjects on the FR-1 schedule of reinforcement, a dosage of chlorpromazine which had significantly increased the frequency of cocaine self-administration behavior in the acute study $(2.0 \mathrm{mg} / \mathrm{kg})$, was administered intramuscularly to four subjects, five minutes before the start of the daily session for five consecutive days. This was done to determine if tolerance would develop rapidly to this effect of chlorpromazine. Saline control pretreatment sessions were conducted immediately before and after the chronic treatment regimen in each subject.

c) Acute Pretreatment (Other Psychomotor Stimulants). Following the determination of the effects of acute and chronic chlorpromazine pretreatment on cocaine self-administration behavior, all subjects were returned to a FR-1 schedule of reinforcement for three days. At this time, the cocaine was replaced with a solution of methylphenidate hydrochloride in sterile saline in four of the eight subjects, and a solution of pipradrol 
hydrochloride in the remaining four subjects. Each of these subjects self-administered these compounds for fourteen days. Those self-administering methylphenidate received $0.05 \mathrm{mg} / \mathrm{kg} /$ injection; whereas, those self-administering pipradrol received $0.01 \mathrm{mg} / \mathrm{kg} /$ injection. Stable baselines of daily drug intake were ascertained during this period. Seven pre-treatment dosages of chlorpromazine, ranging from 0.125 to $8.0 \mathrm{mg} / \mathrm{kg}$ were administered to each of the eight subjects. The pretreatment volume was again held constant at $1.0 \mathrm{cc}$ and pretreatment solutions were prepared using sterile physiologic saline on the day in which they were to be used. Pretreatment dosages were administered intramuscularly five minutes before the onset of the drug access period and at least three days elapsed between pretreatment sessions. Five control pretreatment sessions, i.e., intramuscular injection of $1.0 \mathrm{cc}$ of sterile physiologic saline, were again conducted in each subject.

After the control sessions and chlorpromazine pretreatment sessions had been conducted in these subjects, the psychomotor stimulants being self-administered were again changed. Phenmetrazine hydrochloride, $0.1 \mathrm{mg} / \mathrm{kg} /$ injection, was substituted for methylphenidate and $d$-amphetamine sulfate, $0.025 \mathrm{mg} / \mathrm{kg} /$ injection, was substituted for the pipradrol. The drug pretreatment procedure was repeated in the eight subjects. Following stabilization of total drug intake within fourteen days, each subject was pretreated with at least four dosages of chlorpromazine and with five injections of saline.

\section{Results}

a) Acute Pretreatment (Cocaine). Fig. 1 illustrates the mean percentage change in cocaine self-administration as a function of the pretreatment dosage of chlorpromazine (CPZ). The points represent the mean values obtained from four subjects and the vertical lines indicate the range. The brackets at the left represent the range for twenty saline control pretreatment sessions, five conducted in each subject. CPZ in dosages of $0.125-4.0 \mathrm{mg} / \mathrm{kg}$ produced a mean increase $(15-55 \%)$ in cocaine selfadministration. When the $\mathrm{CPZ}$ pretreatment dosage was increased to $8.0 \mathrm{mg} / \mathrm{kg}$, there was gross evidence of marked CNS depression and catalepsy and cocaine self-administration was significantly depressed. Pretreatment dosages $(0.25-4.0 \mathrm{mg} / \mathrm{kg})$ of chlorpromazine produced an increase in cocaine self-administration during the first, second, and third hours of the session. Pretreatment with $8.0 \mathrm{mg} / \mathrm{kg}$ of $\mathrm{CPZ}$ increased cocaine self-administration only during the first hour of the session. This dosage depressed all behavior during the second, third and fourth hours. During the fourth hour, only pretreatment dosages of $1.0-4.0 \mathrm{mg} / \mathrm{kg}$ of CPZ were effective in increasing cocaine intake. Cocaine intake had returned to control levels with lower pretreatment dosages of CPZ, i.e., 
0.25 and $0.5 \mathrm{mg} / \mathrm{kg}$ by this time. Therefore, both the magnitude and duration of the $\mathrm{CPZ}$ induced increase in cocaine self-administration were dose-related up to a point, i.e., $8.0 \mathrm{mg} / \mathrm{kg}$. Similar results were obtained with all four subjects in this phase of the study.

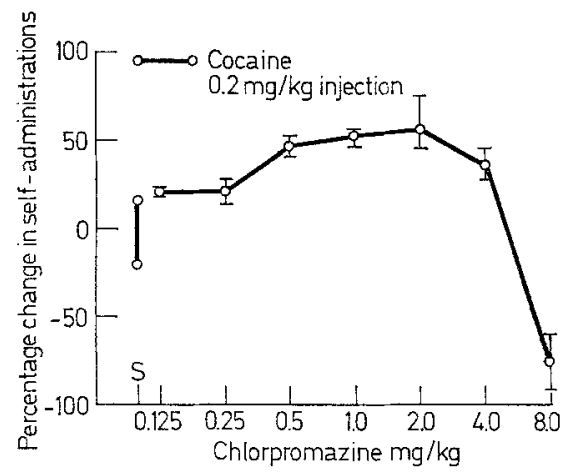

Fig.1. Mean percentage change in cocaine self-administration as a function of the pretreatment dosage of chlorpromazine. Each point represents the mean of four subjects and the vertical lines illustrate the range. The brackets at the left represent the range of change in cocaine-self-administration which occurred following pretreatment with saline. Five of these control sessions were conducted in each subject

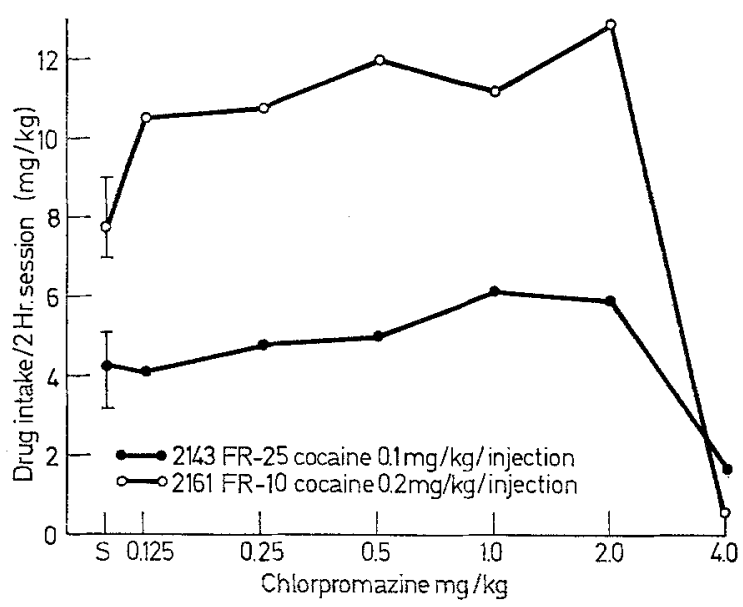

Fig. 2. Cocaine intake as a function of the pretreatment dosage of chlorpromazine in two subjects self-administering cocaine. M2143 was on a FR-25 schedule and M2161 on a FR-10 schedule of reinforcement. Each point represents total cocaine intake for that session in one subject. Vertical lines at the left represent the range of cocaine intake which occurred during five control, i.e., saline pretreatment, sessions. The superimposed point represents mean cocaine intake for these control sessions 
The effect of acute chlorpromazine pretreatment on cocaine selfadministration in subjects on higher fixed ratio schedules of reinforcement is illustrated in Fig. 2 . CPZ in dosages of $0.125-2.0 \mathrm{mg} / \mathrm{kg}$ increased cocaine self-administration in M 2161, who was on a FR-10 schedule of reinforcement for cocaine at a unit dosage of $0.2 \mathrm{mg} / \mathrm{kg}$-injection. However, in M 2143 who was self-administering cocaine at a unit dosage of $0.1 \mathrm{mg} / \mathrm{kg}$ on a FR-25 schedule of reinforcement, only pretreatment

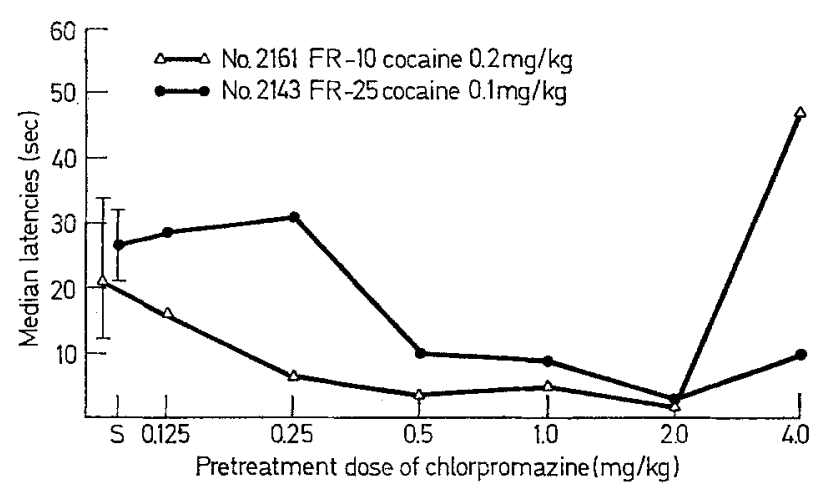

Fig. 3. Median latencies (secs.) in two subjects self-administering cocaine on a FR-10 and FR-25 schedule of reinforcement as a function of the pretreatment dosage of chlorpromazine. The vertical lines and superimposed points at the left indicate the range and mean respectively obtained from five control, i.e., saline pretreatment, sessions conducted in each subject

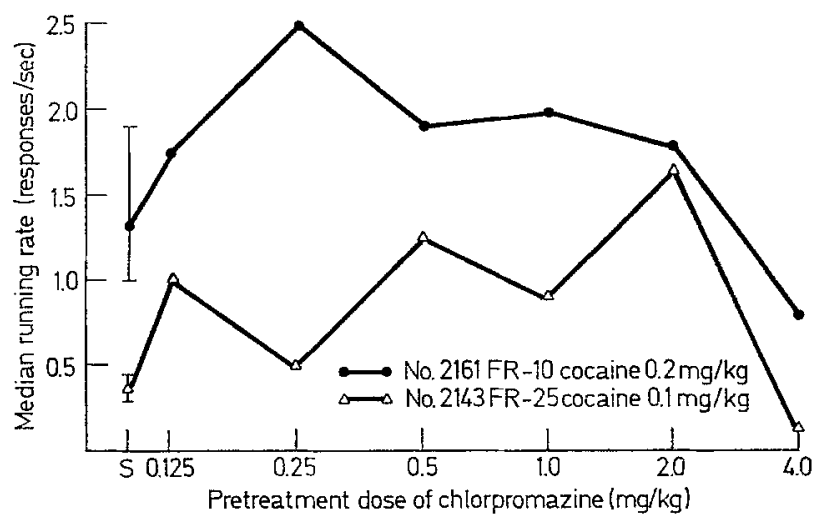

Fig.4. Median running rates (responses per sec) in two subjects self-administering cocaine on a FR-10 and FR-25 schedule of reinforcement as a function of the pretreatment dosage of chlorpromazine. The vertical lines and superimposed points at the left indicate the range and mean respectively, obtained from five control, i.e., saline pretreatment, sessions conducted in each subject 
dosages of 1.0 and $2.0 \mathrm{mg} / \mathrm{kg}$ were effective in increasing cocaine selfadministration. Pretreatment with $4.0 \mathrm{mg} / \mathrm{kg} \mathrm{CPZ}$ almost completely suppressed cocaine reinforced behavior in both subjects. At this dosage, the subjects exhibited marked CNS depression and catalepsy which was quantitatively similar to that produced by the $8.0 \mathrm{mg} / \mathrm{kg}$ dose of CPZ in subjects self-administering cocaine on a FR-1 schedule of reinforcement.

Figs. 3 and 4 illustrate the effects of CPZ pretreatment on median latencies and median running rates respectively in these same two subjects. Median running rate, i.e., rate of responding from the first response to the Nth response on a FR-N schedule of reinforcement, was increased two to three times above that seen during control sessions in M 2143 following pretreatment with $0.125-2.0 \mathrm{mg} / \mathrm{kg}$ of CPZ. A qualitatively similar effect was observed in M 2161 when pretreated with $0.25 \mathrm{mg} /$ $\mathrm{kg}$ of $\mathrm{CPZ}$. Median running rates were greatly reduced in both subjects when the pretreatment dosage was increased to $4.0 \mathrm{mg} / \mathrm{kg}$. Median latencies, i.e., time from the last reinforcement or injection to emission of the first appropriate response, decreased on both subjects as the pretreatment dosage was increased from 0.5 to $2.0 \mathrm{mg} / \mathrm{kg}$. Further increases in pretreatment dosage increased latencies. It appears then that both the ability of CPZ to decrease latencies of responding for this reinforcer and its ability to increase running rates were involved in increasing selfadministration behavior.

b) Chronic Pretrealment (Cocaine). Fig. 5 illustrates the effects of chlorpromazine chronically administered for 5 days, at a dosage of $2.0 \mathrm{mg} / \mathrm{kg}$ in two subjects which were self-administering cocaine at a unit dosage of $0.2 \mathrm{mg} / \mathrm{kg} /$ injection on a FR-1 schedule of reinforcement.

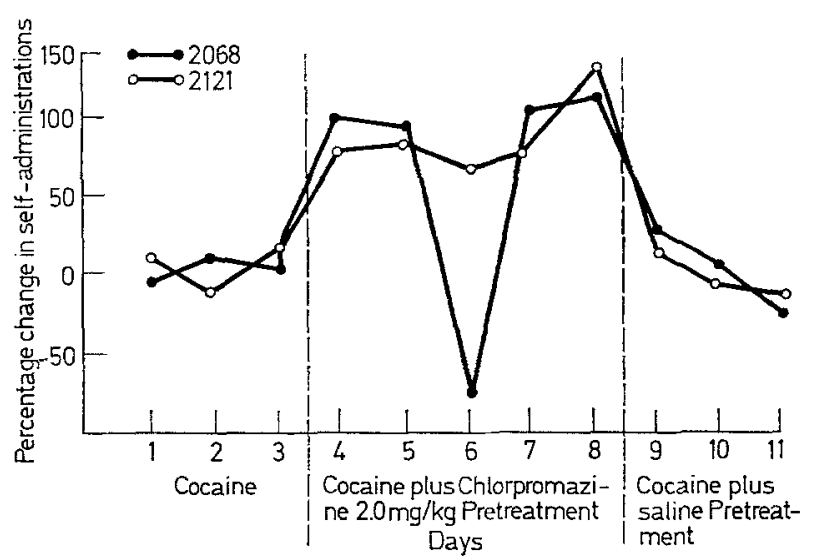

Fig. 5. Percentage change in cocaine self-administration during chronic pretreatment with $2.0 \mathrm{mg} / \mathrm{kg}$ chlorpromazine 
Chlorpromazine increased cocaine self-administration on all five days in M 2121 and on four of the five days in M 2068. The magnitude of this effect was very similar on each of the days in both subjects. Since the magnitude of the increase in cocaine intake remained constant throughout the period of chronic CPZ treatment, there was no evidence of tolerance developing to this action of CPZ. On the third day of treatment in M 2068, a very large decrement in cocaine self-administration occurred and there was profound evidence of general CNS depression. In both subjects, cocaine intake significantly returned toward baseline levels on the day following cessation of $\mathrm{CPZ}$ treatment. More importantly, this session was a saline control pretreatment session. Therefore, there was no

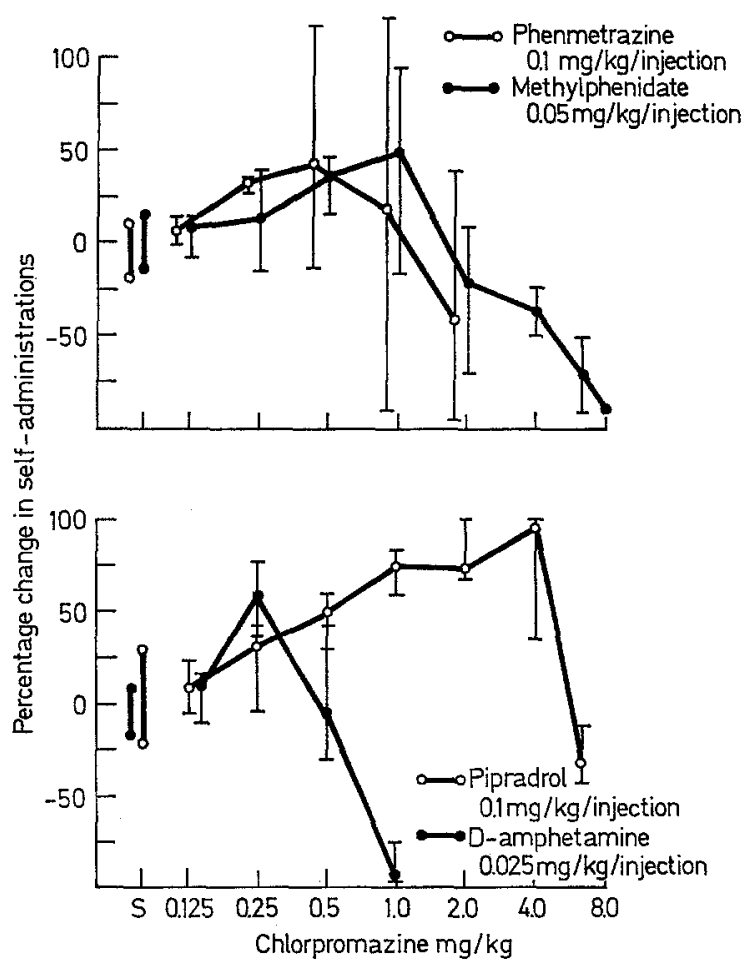

Fig.6. Mean percentage change in phenmetrazine and methylphenidate selfadministration (upper graph) and pipradrol and $d$-amphetamine self-administration (lower graph) as a function of the pretreatment dosage of chlorpromazine. Each point represents the mean of four subjects and the vertical lines illustrate the range. The brackets at the left indicate the range of change in psychomotor stimulant self-administration which occurred following pretreatment with saline. Five of these control sessions were conducted in each of four subjects during the period in which they self-administered each psychomotor stimulant 
evidence that the CPZ-induced increase in cocaine intake had been conditioned. The slight increase in responding above control levels in both subjects on the first day following chlorpromazine pretreatment may have been due to the presence of $\mathrm{CPZ}$ which had not yet been metabolized and excreted.

c) Acute Pretreatment (Other Psychomotor Stimulants). Fig.6 illustrates that acute pretreatment with chlorpromazine increased methylphenidate, phenmetrazine, pipradrol and d-amphetamine self-administration behavior. Table 1 reflects the number of subjects which selfadministered the various psychomotor stimulants at an increased frequency following pretreatment with various dosages of chlorpromazine. Chlorpromazine in dosages of $0.25-1.0 \mathrm{mg} / \mathrm{kg}$ increased phenmetrazine intake. However, increases were not observed in all subjects with all pretreatment dosages. As the pretreatment dosage was increased from $0.25-1.0 \mathrm{mg} / \mathrm{kg}$, variability in this effect increased. This was apparently due to intersubject sensitivity to the general CNS depressant effects of CPZ. Further increases in CPZ pretreatment dosage above $1.0 \mathrm{mg} / \mathrm{kg}$ decreased phenmetrazine self-administration in the majority of subjects. The subjects at these dosages exhibited catalepsy and marked CNS depression.

Pretreatment with 0.5 and $1.0 \mathrm{mg} / \mathrm{kg}$ of $\mathrm{CPZ}$ increased methylphenidate self-administration. Lower dosages increased this behavior in some of the subjects; however, no effect was observed following pretreatment with $0.125 \mathrm{mg} / \mathrm{kg}$ of CPZ. Pretreatment with $2.0,4.0$, and $8.0 \mathrm{mg} / \mathrm{kg}$ of CPZ produced a dose-related depression in methylphenidate self-administration in all subjects. At these dosages, the subjects exhibited extreme motor incapacitation.

Table 1. Number of subjects in which chlorpromazine pretreatment increased psychomotor stimulant self-administration behavior

\begin{tabular}{llllll}
\hline $\begin{array}{l}\text { Pretreatment Dosage } \\
\text { of Chlorpromazine } \\
(\mathrm{mg} / \mathrm{kg})\end{array}$ & \multicolumn{5}{l}{ Psychomotor stimulant self-administered } \\
\cline { 2 - 6 } & Cocaine & $\begin{array}{l}\text { Methyl- } \\
\text { phenidate }\end{array}$ & $\begin{array}{l}\text { Phen } \\
\text { metrazine }\end{array}$ & Pipradrol & $\begin{array}{l}d \text {-amphet- } \\
\text { amine }\end{array}$ \\
\hline 0.125 & $3(4)$ & $0(4)$ & $1(4)$ & $0(4)$ & $1(4)$ \\
0.25 & $3(4)$ & $2(4)$ & $4(4)$ & $1(4)$ & $4(4)$ \\
0.5 & $4(4)$ & $3(4)$ & $3(4)$ & $3(4)$ & $2(4)$ \\
1.0 & $4(4)$ & $3(4)$ & $2(4)$ & $4(4)$ & $0(4)$ \\
2.0 & $4(4)$ & $0(4)$ & $1(4)$ & $4(4)$ & - \\
4.0 & $4(4)$ & $0(4)$ & - & $4(4)$ & - \\
8.0 & $0(4)$ & $0(4)$ & - & $0(4)$ & - \\
\hline
\end{tabular}

$(-)=$ no subjects tested with this pretreatment dosage. 
Pretreatment with $0.125 \mathrm{mg} / \mathrm{kg}$ of CPZ had no effect on $d$-amphetamine self-administration behavior; however, dosages of 0.25 and $0.5 \mathrm{mg} /$ $\mathrm{kg}$ increased $d$-amphetamine intake in the majority of the subjects. Pretreatment with $1.0 \mathrm{mg} / \mathrm{kg}$ of CPZ severely depressed $d$-amphetamine self-administration in all subjects.

Pretreatment with 0.125 and $0.25 \mathrm{mg} / \mathrm{kg}$ of $\mathrm{CPZ}$ had no effect on pipradrol self-administration. However, pretreatment with 0.5, 1.0, 2.0 and $4.0 \mathrm{mg} / \mathrm{kg}$ increased pipradrol self-administration in a dose-related manner. Further increases in pretreatment dosage decreased drug intake below control levels.

\section{Discussion}

The effect of chlorpromazine pretreatment in animals self-administering cocaine is indeed significant. CPZ in the dosages which increased selfadministration behavior produces a dose-related depression in leverresponse frequency for other reinforcers, e.g., food, water and social reinforcement in this species (unpublished observations from this laboratory). Thus, the increased lever-pressing frequency for psychomotor stimulants following CPZ pretreatment may be uniquely related to the nature of this reinforcer, i.e., psychomotor stimulant administration. This effect on psychomotor stimulant self-administration behavior may or may not be related to the schedule of reinforcement. Cocaine intake was increased in subjects on FR-1, FR-10 and FR-25 schedules, however, only fixed ratio schedules of reinforcement were studied in these experiments. The dose of $\mathrm{CPZ}$ required to produce grossly observable severe CNS depression appeared to be inversely related to the value of the FR schedule employed. One perhaps could hypothesize that with the larger ratio requirements, more time was needed to self-administer a sufficient amount of cocaine to counteract the depressant effects of a given dosage of $\mathrm{CPZ}$.

Increases in the frequency of cocaine self-administration may have resulted from the ability of CPZ to antagonize the reinforcing property of cocaine. Wilson et al. have previously demonstrated that decreases in the unit dosage, i.e., dosage per injection, of cocaine resulted in an increase in self-administration frequency over a wide range of reinforcing dosages. If CPZ antagonized the reinforcing property of cocaine, then one would expect to see similar increases in cocaine self-administration frequency.

One could also interpret the results of this study to have occurred due to an antagonism of those effects of cocaine which may be involved in limiting its self-administration, e.g. aversiveness or behavioral disruption. The work of Pickens and Thompson suggests that a primary factor controlling the rate of responding on fixed ratio schedules of cocaine 
reinforcement is the length of post reinforcement pause of ongoing behavior. Results from the present study indicate that chlorpromazine decreases this post reinforcement pause, i.e., decreases the latency following each cocaine injection. This effect in itself would produce an increase in cocaine self-administration behavior.

The work of Stein and Ray provides data which suggests that CPZ may be increasing cocaine self-administration by both of these mechanisms. These investigators studied the effects of CPZ on intracranial selfstimulation in rats. The subjects were presented with two levers; the depression of one led to electrical stimulation of a "reward" area. However, the shock intensity decreased progressively with each lever press, but could be reset to its original level by a single response on the other lever. Apparently the reward threshold was increased by $\mathrm{CPZ}$ treatment, i.e., CPZ antagonized the reinforcing effects of the intracranial stimulation. In addition, the subjects pressed the primary reinforcing lever more frequently. These authors postulated that this effect resulted from the ability of CPZ to antagonize the after-effects, i.e., aversiveness or behavioral dismuption, of the brain shock.

In addition to cocaine, chlorpromazine pretreatment increased the frequency of self-administration of other psychomotor stimulants which are self-administered by the Rhesus monkey. As the pretreatment dosage of CPZ is increased beyond a point, an inverse relationship between pretreatment dosage and self-administration behavior is exhibited. The point at which this function becomes inverse rather than direct may be indicative of the ability of a given psychomotor stimulant to antagonize the behavioral depressant properties of $\mathrm{CPZ}$. Therefore, it appears that chlorpromazine has the ability to antagonize the effect, common to all of the psychomotor stimulants, which determines the amount of these compounds which are self-administered. Wilson et al., have demonstrated that there is some mechanism which functions to regulate the quantity of these compounds which are self-administered.

There are many references in the literature which demonstrate the ability of CPZ to antagonize certain effects of the psychomotor stimulants (Rein; Maickel; Espelin and Done; Benesova and Trinerova). This further suggests that the increase in psychomotor stimulant self-administration seen following pretreatment with $\mathrm{CPZ}$ is due to the ability of CPZ to antagonize those actions of the psychomotor stimulants which function in regulating their self-administration.

\section{References}

Benesova, O., Trinerova, I.: The effects of psychotropic drugs on the cholinergic and adrenergic system. Int. J. Neuropharmacol. 3, 473-478 (1964).

Deneau, G., Inoki, R.: Nicotine self-administration in monkeys. Ann. N.Y. Acad. Sci. 142, 277-279 (1967).

9 Psychopharmacologia (Berl.), Vol.26 
Espelin, D., Done, A. : Amphetamine poisoning. New Eng. J. Med. 278, 1361-1365 (1968).

Maickel, R.: Diverse central effects of chlorpromazine. Int. J. Neuropharmacol. 7, $23-27$ (1968).

Pickens, R., Harris, W.: Self-administration of $d$-amphetamine by rats. Psychopharmacologia (Berl.) 12, 158-163 (1968).

- Meisch, R., McGuire, L.: Methamphetamine reinforcement in rats. Psychon. Sci. 8, 371-372 (1967).

- Thompson, T.: Cocaine-reinforced behavior in rats: Effects of reinforcement magnitude and fixed ratio size. J. Pharmacol. exp. Ther. 161, 122-129 (1968).

Reid, A.: Pharmacological antagonism between chlorpromazine and phenmetrazine in mental hospital patients. Med. J. Aust. 25, 187-188 (1964).

Stein, L., Ray, O.: Brain stimulation reward "thresholds" self-determined in rats. Psychopharmacologia (Berl.) 1, 251-256 (1960).

Wilson, M. C., Hitomi, M., Schuster, C. R.: Psychomotor stimulant self-administration as a function of dosage per injection in the Rhesus monkey. Psychopharmacologia (Berl.) (submitted for publication).

Woods, J., Schuster, C. R.: Reinforcement properties of morphine, cocaine and SPA as a function of unit dose. Int. J. Addict. 3, 231-237 (1968).

Yanagita, T., Denean, G., Seevers, M.: Evaluation of pharmacological agents in the monkey by long-term intravenous self or programmed administration. Excerpta Med. Int. Congr. Series 87, 453-457 (1965).

Charles R. Schuster, Ph. D.

Department of Psychiatry

University of Chicago

950 East 59 th st.

Chicago, Illinois 60637, U.S.A. 